Neuroepidemiology 2008;31:68

DOI: $\underline{10.1159 / 000140098}$

\section{Risk Factors for Dementia}

\section{Amanda G. Thrift ${ }^{\mathrm{a}, \mathrm{b}}$, , Velandai K. Srikanth ${ }^{\mathrm{c}}$}

${ }^{a}$ Baker Heart Research Institute, ${ }^{b}$ Departments of Epidemiology \& Preventive Medicine and ${ }^{\mathrm{C}}$ Neurosciences, Department of Medicine, Monash University, and d National Stroke Research Institute, Heidelberg Repatriation Hospital, Melbourne, Vic., Australia

Elucidating factors that predispose to vascular dementia over and above those that predispose to stroke is an important area for research. Identification of these factors would be useful for a number of reasons, including better targeting of treatments to prevent dementia, in both those with and without stroke.

In their letter to the editor, Potluri et al. [1], outline a clinical audit conducted on 440 patients with vascular dementia and 2,575 patients with ischemic stroke within their teaching hospital in Birmingham, UK. When comparing the two groups they found that the prevalence of vascular risk factors was less in patients identified with vascular dementia than in those with ischemic stroke, and concluded that only age and stroke were independently associated with the development of vascular dementia. In contrast, risk factors for ischemic stroke were similar to those identified previously [2]. They concluded that this disparity in prevalence of risk factors between the two conditions is surprising. However, this may not be such a surprising finding when one takes into account of couple of very important methodological issues.

Firstly, the risk factors identified may be subject to some misclassification bias [3]. This may occur when there is no systematic method for obtaining information on risk factors. Different clinicians may collect this information in different ways. This will cause problems if the information collected is systematically different between patient groups, resulting in differential misclassification. For example, information about atrial fibrillation may not be requested in patients with vascular dementia because it is not considered important in people with this disease. Therefore, the prevalence of atrial fibrillation in these patients may be underestimated. In addition, the categorization of the presence or absence of some risk factors may differ. For example, some clinicians may not classify a patient as hypertensive unless their systolic blood pressure is greater than $160 \mathrm{~mm} \mathrm{Hg}$, particularly older patients. Others may diagnose hypertension when the patient has a blood pressure greater than $140 / 90 \mathrm{~mm} \mathrm{Hg}$. If this diagnostic threshold is different between groups then this may result in an underestimation of the risk factor in one group. It is not clear from the letter by Potluri et al. that risk factor and disease classification was standardized and systematic.

There may also be some misclassification of the disease. It is possible that the definition of vascular dementia, when obtained from medical records, is not robust. If people who do not have this condition are incorrectly allocated to this diagnosis, and if their condition is not related to vascular disease, then risk factors for vascular disease in this group will be underestimated.

The findings will also differ depending on the comparison group used. When risk factors are compared between patients with vascular disease and those with ischemic stroke, then any risk factors identified for vascular disease will only be those over and above those for ischemic stroke. However, it is not clear that this is the case. A glance at table 1 will show us that only 18 people in the group with dementia had not had a stroke. Thus, there will be heavy reliance on these 18 cases in the resulting odds ratio obtained. If the comparison group comprises those who have been diagnosed with neither dementia nor ischemic stroke, then the risk factors identified will be more realistic.

Finally, and most importantly, there remains the problem of selecting which variables to include in the model. This is particularly important when determining whether or not to control for factors that may be on the causal pathway between the vascular factors and dementia. Controlling for stroke could be considered overfitting the model as one is then also controlling for many of the risk factors that led to the development of stroke. Hosmer and Lemeshow [4] indicate that overfitting is often characterized by unrealistically large estimated odds ratios. Indeed an odds ratio of 583, as reported in this correspondence, should alert one to the fact that there is something untoward going on here, and further investigation of the reasons for this should be explored.

\section{References}

1 Potluri R, Natalwala A, Uppal H, Heun R: Cardiovascular risk factors in vascular dementia and ischaemic stroke. Neuroepidemiology 2008; 31:67.

2 Thrift AG, Gilligan AK, Donnan GA: Risk factors and protective factors: how to improve primary prevention of cerebrovascular disease; in Fieschi C, Fisher M (eds): Prevention of Ischemic Stroke. London, Martin Dunitz, 2000.

3 Armstrong BK, White E, Saracci R: Principles of Exposure Measurement in Epidemiology. Oxford, Oxford University Press, 1992, p 68.

4 Hosmer DW Jr, Lemeshow S: Applied Logistic Regression. New York, John Wiley \& Sons, 1989, p 83.

Associate Prof. A. Thrift

Baker Heart Research Institute, 75 Commercial Road

Melbourne, Vic. 3004 (Australia)

Tel. +61 38532 1111, Fax +61 385321100

E-Mail Amanda.Thrift@baker.edu.au

\section{KARGER}

Fax +41613061234 E-Mail karger@karger.ch www.karger.com
(C) 2008 S. Karger AG, Base

0251-5350/08/0311-0068\$24.50/0 